\title{
The association between stressful life events and perceived quality of life among women attending infertility treatments: the moderating role of coping strategies and perceived couple's dyadic adjustment
}

\author{
Maria Clelia Zurlo ${ }^{1 *}$ (D), Maria Francesca Cattaneo Della Volta ${ }^{2}$ and Federica Vallone ${ }^{2}$
}

\begin{abstract}
Background: Research highlighted that Stressful Life Events have high incidence among infertile patients and significant impact on physical and medical parameters related to reproductive functions, but their potential role among factors influencing the infertile patients' perception of fertility-related Quality of Life (QoL) has not been explored. The present study aims to investigate the associations of Stressful Life Events (Stressful events in the family of origin, In family pre-existing pregnancy difficulties, Health problems in childhood) with perceived fertilityrelated QoL in women attending infertility treatments, examining the potential moderating role of adopted coping strategies and perceived couple's dyadic adjustment.

Methods: A questionnaire consisting of Socio-demographics and Infertility-related characteristics, Stress-inducing events in the couples' lives Questionnaire (FLS), Coping Orientations to Problem Experienced (COPE), Dyadic Adjustment Scale (DAS), and Core and Treatment subscales of Fertility Quality of Life (FertiQoL) was administered to 266 women attending infertility treatments. A descriptive correlational design with cross-sectional comparison was used. Results Logistic Regression Analyses after adjusting for socio-demographic and infertility-related characteristics revealed that women who reported Stressful events in the family of origin and In family pre-existing pregnancy difficulties were more likely to report lower levels of perceived Core QoL, while women who reported Health problems in childhood were more likely to report lower levels of perceived Treatment QoL. Couple's dyadic adjustment and specific coping strategies were significantly associated with perceived Core and Treatment QoL and they also significantly moderated the associations between stressful life events and perceived QoL.

Conclusions: Data provided original evidence on the strong association between stressful life events and perceived fertility-related QoL also highlighting individual and couples' resources to define counselling interventions with women attending infertility treatments.
\end{abstract}

Keywords: Infertility, Stressful life events, Quality of life, Coping strategies, Couple's dyadic adjustment

\footnotetext{
* Correspondence: zurlo@unina.it

${ }^{1}$ Department of Political Sciences, University of Naples Federico II, Via L.

Rodinò 22, 80138 Naples, Italy

Full list of author information is available at the end of the article
}

(c) The Author(s). 2019 Open Access This article is distributed under the terms of the Creative Commons Attribution 4.0 International License (http://creativecommons.org/licenses/by/4.0/), which permits unrestricted use, distribution, and reproduction in any medium, provided you give appropriate credit to the original author(s) and the source, provide a link to the Creative Commons license, and indicate if changes were made. The Creative Commons Public Domain Dedication waiver (http://creativecommons.org/publicdomain/zero/1.0/) applies to the data made available in this article, unless otherwise stated. 


\section{Background}

Infertility is clinically described as a disease of the reproductive system defined by the failure to achieve a clinical pregnancy after 12 months or more of regular unprotected sexual intercourse [1], affecting 9-15\% of couples worldwide [2]. Research widely recognized that infertility is a distressing experience [3-5] that may significantly affect perceived levels of quality of life (QoL) [6-11] and psychological health [12-15], and implies attempts of re-definition by searching for causes and meanings to re-establish personal control and satisfactory (QoL) [16-18].

QoL is a multidimensional construct defined as the perception of individuals of their position in the context of their culture and values system and in relation to their goals, expectations, standards, and concerns, which comprises psychological, physical, social and environmental perceived functioning and health [19]. In the same perspective, the construct of the fertility quality of life (FertiQoL) has been developed with the aim of specifically address both dimensions of perceived emotional, physical, relational and social QoL (Core FertiQoL), and dimensions of accessibility and perceived quality of services, quality of interactions with the medical staff, physical and psychological consequences of the medical treatments (Treatment FertiQoL) [20-22]. Therefore, research identified several individual factors (i.e., gender [8, 23], age [23-25] and coping strategies $[26,27])$, infertility-related factors (i.e., type of diagnosis, type of treatment and duration of infertility $[6,27,28]$ ), and relational factors (i.e., quality of marital relationship [29-31]), influencing perceived levels of psychological health and QoL.

Research also highlighted that stressful life events have to be considered as factors widely influencing physical and psychological health parameters [32-37] and perceived levels of QoL [38-42]. Therefore, considering infertility research, several studies showed that the presence of stressful events in the family of origin (e.g., divorce, financial problems, deaths, maltreatment), in family pre-existing pregnancy difficulties (e.g., unwanted child, stillborn children, abortion), and health problems in childhood (e.g., injuries, illness, hospitalization) is frequently reported in the biographical background of infertile patients [43-45], revealing a significant impact on relevant physical and medical parameters related to the reproductive functions, such as menstrual cycle regularity [46], semen quality [47], and pregnancy outcome after In Vitro Fertilization (IVF) [48-50].

Nevertheless, according to previous research on couple counseling and therapy with infertile patients [17], the couple's biographical background may also have a significant impact on the perception and definition of the current infertility experience at individual, relational and social level. Indeed, previous research highlighted that the adaptation process to an aversive event consists of appraisals of both primary control (i.e., appraisal of possibilities to modify the situation to reduce its negative impact) and secondary control (i.e., appraisals of possibilities to modify the appraisal of circumstances to promote adaptation to them). In particular, secondary control appraisal may include different strategies aiming to enhance adjustment, such as interpretative control (i.e., attempts to give meaning on the basis of previous experiences); cognitive control (i.e., attempts to think and redefine the situation), predictive control (i.e., attempts to predict future events to avoid disappointment and pain previously experienced), vicarious control (i.e., attempts to control experience ascribing it to an authoritative other) and retrospective control (i.e., attempts to identify protective factors in a past negative experience with the aim of consider it avoidable in the future) [16]. Consequently, on the basis of the research reported above, previous stressful life events may be hypothesised as influencing the quality and the effectiveness of control strategies adopted by infertile patients and, therefore, their perceived levels of QoL.

\section{Aims}

Although previous studies suggest that stressful life events have a significant impact on essential parameters for the reproductive success, to date, to the best of our knowledge, little is known concerning the associations between the presence of stressful life events and perceived levels of QoL in infertile patients.

Therefore, the present study aims at analysing the potential association of Stressful Life Events (i.e., Stressful events in the family of origin, In family pre-existing pregnancy difficulties, Health problems in childhood) with perceived Core and Treatment QoL in women attending infertility treatments. Furthermore, considering the significant role exerted by individual resources (i.e., coping strategies) [26, 27, 51-55], and by relational resources (i.e., perceived couple's dyadic adjustment) $[3-5,29,31]$ invested in dealing with infertility, the present study aims at testing the potential moderating role of adopted coping strategies and of perceived couple's dyadic adjustment in the relationship between experienced Stressful Life Events and perceived levels of Fertility-related Core and Treatment QoL.

\section{Methods}

\section{Study design and participants}

The present cross-sectional study was conducted in collaboration with 9 Italian Centres of Assisted Reproduction of Naples, Udine, and Brescia between March 2016 and January 2017. The study was approved by the Ethical Committee of Psychological Research of the University of Naples Federico II and research was performed in accordance with the 1964 Helsinki declaration and its later 
amendments or comparable ethical standards. Prior to data collection, the Heads of all Departments of the University were informed about the purpose of the study and data collection procedures and their consent was acquired. Chairmen were asked to give the authorization for administering a questionnaire in their centres and, after obtaining their adhesion to the project, women undergoing infertility treatments were asked to participate in the study before their medical appointment. Participants were female members of couples that had been diagnosed with infertility (Male Factor; Female Factor; Combined Male and Female Factor or Unexplained), with all aetiologies of infertility. Overall, 300 women were asked by their physician to participate in the study, and 266 out of 300 women (response rate $=88.67 \%$ ) completed a questionnaire lasting $20-30 \mathrm{~min}$ (one session) in a quiet room setting in the medical centre. One of the authors was present to answer any queries raised by participants.

\section{Measures}

A questionnaire composed of six sections was submitted. All variables and measures investigated are displayed in Table 1.

\section{Statistical analysis}

Data were analysed using Statistical Package for Social Science (SPSS, Version 21). Firstly, a number of descriptive analyses of socio-demographic and infertility-related characteristics of study participants were conducted. All the study variables were dichotomised. Age and Duration of Infertility were dichotomised referring to the means of our sample. Educational Level (Senior School education/College education), Type of Diagnosis (Male Factor, Female Factor, Combined Factor and Unexplained Factor), Type of Treatment (In vitro fertilization,
IVF; Intracytoplasmic sperm injection, ICSI; Intrauterine insemination, IUI), and Stressful Life Events were coded as absence/presence. Coping Strategies, Total Dyadic Adjustment, and FertiQoL subscales scores were dichotomised referring to the cut-off scores of the validation studies reported in Table 1. Therefore, descriptive analyses of frequencies and percentages of the presence of Stressful Life Events, recourse to Coping Strategies, and perception of Total Dyadic Adjustment and Core and Treatment FertiQoL were carried out. Afterward, Logistic Regression Analyses (method: enter, first indicator contrast; entry criterion: $p<0.05$; removal criterion: $p>$ 0.01 , and Hosmer and Lemeshow Goodness-of-fit statistic fixed at $p>0.05)$ were separately run to determine main associations of Stressful Life Events, Coping Strategies, and Total Dyadic Adjustment with perceived Core and Treatment FertiQoL. Finally, a further set of Logistic Regression Analyses was carried out to test the potential significant interactions between Stressful Life Events and both adopted Coping Strategies and perceived Total Dyadic Adjustment in predicting perceived levels of Core and Treatment FertiQoL. Relevant Sociodemographic and Infertility-related characteristics (Age, Educational Level, Type of Diagnosis, Type of Treatment and Duration of Infertility) were included in the Logistic Regression Analyses as control variables in order to consider their potential influence on the model parameters. All the different hypotheses have been tested carrying out separated Logistic Regression Analyses.

\section{Results}

Table 2 provides data on Socio-demographic and Infertility-related characteristics. All the 266 women had a diagnosis of primary infertility.

Table 1 Variables considered in the questionnaire and description of measures

\begin{tabular}{|c|c|c|}
\hline Dimensions & Measures & Variables \\
\hline Socio-demographic Characteristics & Single item Questions (2 items) & Age in years Educational Level (Senior School/ College) \\
\hline Infertility Related Characteristics & Single Item Questions (3 items) & $\begin{array}{l}\text { Type of Diagnosis (Male, Female, Combined, Unexplained) } \\
\text { Type of Treatment (IVF, ICSI, IUI) Duration of Infertility in years }\end{array}$ \\
\hline Stressful Life Events & $\begin{array}{l}\text { Stress-inducing events in the couples' } \\
\text { lives Questionnaire (FLS) [43] (3 items) }\end{array}$ & $\begin{array}{l}\text { Stressful events in the family of origin (Absence/Presence) } \\
\text { In family pre-existing pregnancy difficulties (Absence/Presence) } \\
\text { Health problems in childhood (Absence/Presence) }\end{array}$ \\
\hline \multirow[t]{5}{*}{ Coping Strategies } & \multirow{5}{*}{$\begin{array}{l}\text { Coping Orientations to Problem Experienced- } \\
\text { New Italian version (COPE-NVI) }[56,57] \\
\text { (60 items, } 5 \text {-point scale) }\end{array}$} & Problem Solving (Cronbach a = 0.83; cut-off $=32.0)$ \\
\hline & & Positive Attitude (Cronbach a = 0.76; cut-off = 30.9) \\
\hline & & Social Support (Cronbach a = 0.91; cut-off = 27.7) \\
\hline & & Avoidance $($ Cronbach $a=0.70$; cut-off $=23.5)$ \\
\hline & & Turning to religion $($ Cronbach $a=0.85$; cut-off $=22.7)$ \\
\hline Dyadic Adjustment & $\begin{array}{l}\text { Dyadic Adjustment Scale (DAS) }[58,59] \\
\text { (32 items, 6-point scale) }\end{array}$ & $\begin{array}{l}\text { Total Score (satisfaction, cohesion, consensus, affectional } \\
\text { expression) (Cronbach } a=0.93 ; \text { cut-off }=115.0 \text { ) }\end{array}$ \\
\hline \multirow[t]{2}{*}{ Fertility Quality of Life } & \multirow{2}{*}{$\begin{array}{l}\text { Fertility Quality of Life Questionnaire } \\
\text { (FertiQoL) [20-22] (36 items, 5-point scale) }\end{array}$} & Core FertiQoL (Cronbach a = 0.92; cut-off= 54.6) \\
\hline & & Treatment FertiQoL (Cronbach $a=0.92 ;$ cut-off $=60.4)$ \\
\hline
\end{tabular}


Table 2 Socio-demographic and infertility-related characteristics of study participants $(N=266)$

\begin{tabular}{lll}
\hline Characteristics & Value & Range \\
\hline Age $[$ Mean (SD)] & $34.2(3.83)$ & [22-49] \\
$\quad \leq 34$ years $[n(\%)]$ & $146(54.9 \%)$ & \\
$>34$ years $[n(\%)]$ & $120(45.1 \%)$ & \\
Educational Level $[n(\%)]$ & & \\
$\quad$ Senior School & $171(64.3 \%)$ & \\
College & $95(35.7 \%)$ & \\
Type of Diagnosis [n (\%)] & & \\
Male Factor & $89(33.5 \%)$ & \\
Female Factor & $74(27.8 \%)$ & \\
Combined Factor & $61(22.9 \%)$ & \\
Unexplained & $42(15.8 \%)$ & \\
Type of Treatment $[n(\%)]$ & $150(56.4 \%)$ & \\
IVF & $85(32.0 \%)$ & \\
ICSI & $31(11.6 \%)$ & \\
IUI & $3.0(2.38)$ & \\
Duration of infertility [Mean (SD)] & $199(74.8 \%)$ & \\
$\leq 3$ years $[n(\%)]$ & $67(25.2 \%)$ & \\
$>3$ years [n (\%)] &
\end{tabular}

As regards the presence of Stressful life events, Stressful events in the family of origin $(N=130 ; 48.9 \%)$ was the most frequently reported, followed by In Family preexisting pregnancy difficulties $(N=128 ; 48.1 \%)$ and Health problems in childhood $(N=102 ; 38.3 \%)$. As regards perceived levels of Core and Treatment QoL, 57
(21.4\%) women reported low levels of Core FertiQoL and $80(30.1 \%)$ low levels of Treatment FertiQoL.

As regards the adopted Coping Strategies, the recourse to Social Support was the most frequently reported $(N=$ 189; 71.0\%), followed by Positive Attitude $(N=171$; $64.3 \%)$, Problem Solving $(N=164 ; 61.6 \%)$, Avoidance $(N=160 ; 60.1 \%)$, and Turning to Religion $(N=89$; $33.4 \%)$. Finally, as regards perceived couple's dyadic adjustment, 97 women (36.5\%) reported high levels of Total Dyadic Adjustment.

Table 3 displays significant associations emerged from Logistic Regression Analyses. With respect to main effects, findings highlighted that the presence of Stressful events in the family of origin and In family pre-existing pregnancy difficulties was significantly associated with lower perceived levels of Core FertiQoL, while the presence of Health problems in childhood was significantly associated with lower perceived levels of Treatment FertiQoL. Moreover, with respect to main associations of adopted coping strategies with perceived QoL, findings highlighted that high recourse to both active coping strategies (i.e., Positive Attitude and Social Support) and Avoidance/distancing coping strategies was significantly associated with high perceived levels of Core and Treatment FertiQoL, while high recourse to Problem Solving coping strategy was significantly associated with high levels of perceived Treatment FertiQoL. Finally, with respect to main associations of perceived couple's dyadic adjustment with perceived QoL, data revealed that high perceived levels of Total Dyadic Adjustment were significantly associated with high perceived levels of both Core and Treatment FertiQoL.

Table 3 Regressions: stressful life events, coping strategies and couple's dyadic adjustment against FertiQoL subscales

\begin{tabular}{|c|c|c|c|c|}
\hline & \multicolumn{2}{|c|}{ Core FertiQoL } & \multicolumn{2}{|c|}{ Treatment FertiQoL } \\
\hline & OR & $95 \% \mathrm{Cl}$ & $\mathrm{OR}$ & $95 \% \mathrm{Cl}$ \\
\hline Stressful events in the family of origin & $0.45^{*}$ & $0.32-0.98$ & 0.18 & $0.52-3.25$ \\
\hline In family pre-existing pregnancy difficulties & $0.66^{* *}$ & $0.37-0.92$ & 0.37 & $0.24-2.84$ \\
\hline Health problems in childhood & 0.80 & $0.59-4.54$ & $0.44^{*}$ & $0.23-0.92$ \\
\hline Problem Solving & 0.76 & $0.51-3.43$ & $3.21 * *$ & $1.98-6.43$ \\
\hline Positive Attitude & $2.98^{*}$ & $1.76-5.83$ & $3.54^{*}$ & $2.11-8.49$ \\
\hline Avoidance & $2.57^{*}$ & $1.84-6.33$ & $3.03^{*}$ & $2.11-7.42$ \\
\hline Social Support & $3.25^{* *}$ & $2.24-7.12$ & $2.98^{*}$ & $1.65-6.83$ \\
\hline Das Tot & $2.56^{*}$ & $1.61-6.89$ & $3.53^{*}$ & $2.80-7.52$ \\
\hline Stressful events in the family of origin $\times$ Positive Attitude & $2.95^{*}$ & $1.52-7.40$ & 2.53 & $0.83-3.85$ \\
\hline Stressful events in the family of origin $\times$ Das Tot & $2.31^{*}$ & $1.54-7.11$ & 1.87 & $0.91-3.54$ \\
\hline In family pre-existing pregnancy difficulties $x$ Avoidance & $0.43^{*}$ & $0.21-0.89$ & $0.39^{* *}$ & $0.12-0.81$ \\
\hline In family pre-existing pregnancy difficulties $x$ Social Support & $3.96^{* *}$ & $2.68-9.32$ & $3.24^{*}$ & $2.13-7.32$ \\
\hline In family pre-existing pregnancy difficulties $\times$ Das Tot & $3.15^{*}$ & $1.35-8.31$ & 2.11 & $0.90-3.24$ \\
\hline Health problems in childhood $x$ Problem Solving & $3.76 * *$ & $2.61-8.21$ & $3.09^{*}$ & $2.34-7.42$ \\
\hline Health problems in childhood $\times$ Das Tot & 2.67 & $0.89-3.76$ & $3.51^{* *}$ & $2.25-8.17$ \\
\hline
\end{tabular}

${ }^{*} p<0.05 ;{ }^{* *} p<0.01$. Controlled by Age, Educational Level, Type of Diagnosis, Type of Treatment, and Duration of Infertility 
With respect to interaction analyses, data revealed that negative associations between the presence of Stressful events in the family of origin and perceived levels of Core FertiQoL were significantly moderated by the recourse to Positive Attitude coping strategy, and that negative associations between the presence of Health problems in childhood and perceived levels of Treatment FertiQoL were significantly moderated by the recourse to Problem Solving coping strategy. Moreover, negative associations between the presence of In family pre-existing pregnancy difficulties and perceived Core FertiQoL were significantly buffered by the recourse to Social Support coping strategy, and, conversely, significantly increased by the recourse to Avoidance/Distancing coping strategies. Finally, the negative associations between the presence of all types of Stressful Life Events and perceived levels of both Core and Treatment FertiQoL were found significantly moderated by high perceived levels of couple's dyadic adjustment.

\section{Discussion}

According to previous studies [43-45], data confirmed a significant incidence of all types of Stressful Life Events among the women attending infertility treatments considered, highlighting that $48.9 \%$ of women reported Stressful events in the family of origin, $48.1 \%$ reported In family pre-existing pregnancy difficulties, and $38.3 \%$ Health problems in childhood. Moreover, concerning perceived levels of QoL, data also revealed the impact of infertility experience and medical treatments showing that $21.4 \%$ of women reported low levels of Core FertiQoL and 30.1\% low levels of Treatment FertiQoL.

Data also supported the hypothesis of a significant association between the presence of Stressful Life Events and low perceived levels of fertility-related Core and Treatment QoL. In particular, it emerged that women reporting both Stressful events in the family of origin and In family preexisting pregnancy difficulties were more likely to perceive significantly lower levels of Core FertiQoL (i.e., lower levels of perceived relational, emotional, physical and social QoL) when dealing with infertility experience. Moreover, it emerged that women reporting Health problems in childhood were more likely to perceive lower levels of Treatment FertiQoL, inducing to emphasise the role of early experiences of illness and hospitalisation on the infertile patients' perception of medical treatments. In this perspective, findings suggested that there is a need to increase consideration of the potential impact of Stressful Life Events on the infertility experience and, therefore, the organisation of infertility counseling interventions and therapy before, during and after treatments, should also carefully address the exploration of individual, relational and transgenerational dimensions associated to Stressful Life Events to identify factors influencing individual and couple risk and resources, meanings of wish for a child and motivation for infertility treatment.

Nonetheless, data also highlighted the positive moderating role exerted by specific individual and relational resources, such as the recourse to active coping strategies (i.e., Positive Attitude, Problem Solving, and Social Support) and the perception of a satisfactory couple's dyadic adjustment. In particular, in infertile women experiencing the presence of stressful events in the family of origin, the recourse to Positive Attitude (i.e., patients' capability to preserve an active and optimistic attitude) was found having a significant role in enhancing perceived Core QoL. Moreover, in women reporting experiences of health problems in childhood, the adoption of coping strategies centred on Problem Solving (i.e., patients' capability to actively redefine, understand and face medical aspects of infertility diagnosis and treatments) was found having a positive and significant influence on perceived levels of Treatment QoL. Furthermore, in the presence of more specific in family pre-existing pregnancy difficulties, the recourse to coping strategies centred on Social Support (i.e., patients' capability to social sharing and emotional disclosure) was found having a significant influence on perceived levels of Core and Treatment QoL. Conversely, the recourse to Avoidance/distancing coping strategies was not adequate to face the psychological impact of the repetition of previous familiar pregnancy difficulties in patients' current experience, resulting in significantly lower levels of Core and Treatment QoL.

Finally, findings emphasised the role of perceiving a satisfactory and gratifying couple's relationship, able to fulfil the needs for consensus, cohesion, security, and emotional involvement to counteract the negative impact of all previous stressful and adverse events considered on perceived levels of QoL, by sharing negative feelings, worry and tension related to infertility and medical treatments.

In this perspective, the present study shared the aim of ESHRE guidelines [60] to promote an optimal management of psychosocial care, providing evidence-based information to be applied by professionals from the field of infertility and medically assisted reproduction to enhance tailored and customized interventions by including the evaluation of presence, types, and severity of previous Stressful Life Events as well as of individual and relational resources in terms of coping profiles and couple's adjustment.

However, despite these findings, some limitations should be mentioned. Firstly, the present research has a cross-sectional design, and therefore no cause - effect relationships between predictors and outcomes investigated can be suggested. Secondly, the measures used were selfreport, increasing the risk of social desirability bias. Thirdly, only the moderating role of coping strategies and 
perceived dyadic adjustment were considered in the present study, while further research could be developed addressing the potential impact of other variables and other personality characteristics (e.g., personality factors, defence mechanisms, attributional styles, control strategies) which may play a role in predicting QoL in infertile patients. Furthermore, future research could also focus on the potential impact of both stressful life events and perceived fertility-related QoL on relevant medical parameters and pregnancy outcomes. Finally, further research should be developed to specifically focus on the impact of Stressful Life Events on fertility-related QoL among male infertile patients, which could give useful information for psychological interventions for both individuals and couples.

\section{Conclusions}

In conclusion, the present study provided new evidence on the associations between the experience of Stressful Life Events and perceived levels of fertility-related QoL in women undergoing infertility treatments, identifying specific risk and protective factors related to their biographical background to be considered for developing targeted counseling interventions to support and enhance optimal adaptation processes to infertility treatments.

\begin{abstract}
Abbreviations
COPE: Coping Orientations to Problem Experienced; DAS: Dyadic Adjustment Scale; FertiQoL: Fertility-related Quality of Life; FLS: Stress-inducing events in the couples' lives Questionnaire; ICSI: Intracytoplasmic sperm injection; IUI: Intrauterine insemination; IVF: In Vitro Fertilization; QoL: Quality of Life; SPSS: Statistical Package for Social Science
\end{abstract}

\section{Acknowledgements}

The authors are thankful to all women who participated in this study.

\section{Ethical approval and consent to participate}

The study was approved by the Ethical Committee of Psychological Research of the University of Naples Federico II and research was performed in accordance with the 1964 Helsinki declaration and its later amendments or comparable ethical standards. Verbal and written informed consent was obtained from each patient prior to participating in the study.

\section{Authors' contributions}

The following co-authors contributed to de manuscript: MCZ: study conception and design. MFCDV and FV: Acquisition of data. MCZ, MFCDV and FV: Analysis and interpretation of data. MCZ, MFCDV, and FV: Drafting of manuscript. MCZ, MFCDV, and FV: Critical revision. All authors read and approved the final manuscript.

\section{Funding}

This research did not receive any specific grant from funding agencies in the public, commercial, or not-for-profit sectors.

\section{Availability of data and materials}

Data and all other materials for this study are kept at the Department of Political Sciences, University of Naples Federico II. The datasets generated and/or analysed during the current study are not publicly available due to the terms of consent to which the participants agreed but available from the corresponding author upon reasonable request.

\section{Consent for publication}

Not applicable.

\section{Competing interests}

The authors declare that they have no competing interests.

\section{Author details}

${ }^{1}$ Department of Political Sciences, University of Naples Federico II, Via L. Rodinò 22, 80138 Naples, Italy. ${ }^{2}$ Department of Humanities, University of Naples Federico II, Via Porta di Massa 1, 80133 Naples, Italy.

Received: 4 July 2018 Accepted: 16 October 2019

Published online: 21 November 2019

\section{References}

1. Zegers-Hochschild F, Adamson GD, de Mouzon J, Ishihara O, Mansour R, Nygren K, Sullivan E, van der Poel S. The International Committee for Monitoring Assisted Reproductive Technology (ICMART) and the World Health Organization (WHO) revised glossary on ART terminology. Fertil Steril. 2009;92(5):1520-4. https://doi.org/10.1016/j.fertnstert.2009.09.009.

2. Boivin J, Bunting L, Collins JA, Nygren KG. International estimates of infertility prevalence and treatment-seeking: potential need and demand for infertility medical care. Hum Reprod. 2007;22(6):1506-12. https://doi.org/10. 1093/humrep/dem046.

3. Cserepes RE, Kollár J, Sápy T, Wischmann T, Bugán A. Effects of gender roles, child wish motives, subjective well-being, and marital adjustment on infertility-related stress: a preliminary study with a Hungarian sample of involuntary childless men and women. Arch Gynecol Obstet. 2013;288(4): 925-32. https://doi.org/10.1007/s004-013-2835-7.

4. Ying $L Y$, Wu LH, Loke AY. Gender differences in experiences with and adjustments to infertility: a literature review. Int J Nurs Stud 2015;52(10): 1640-1652. https://doi.org/https://doi.org/10.1016/j.jinurstu.2015.05.004.

5. Peterson $\mathrm{BD}$, Newton $\mathrm{CR}$, Rosen $\mathrm{KH}$. Examining congruence between partners' perceived infertility-related stress and its relationship to marital adjustment and depression in infertile couples. Fam Process. 2003:42(1):5970. https://doi.org/10.1111/j.1545-5300.2003.00059.x.

6. Huppelschoten AG, van Dongen AJCM, Verhaak CM, Smeenk JMJ, Kremer JAM, Nelen WLDM. Differences in quality of life and emotional status between infertile women and their partners. Hum Reprod. 2013;28(8):216876. https://doi.org/10.1093/humrep/det239.

7. Karaca N, Karabulut A, Ozkan S, Aktun H, Orengul F, Yilmaz R, Ates S, Batmaz $G$. Effect of IVF failure on quality of life and emotional status in infertile couples. Eur J Obstet Gynecol Reprod Biol. 2016;206:158-63. https://doi.org/ 10.1016/j.ejogrb.2016.09.017.

8. Ragni G, Mosconi P, Baldini MP, Somigliana E, Vegetti W, Caliari I, Nicolosi AE. Health-related quality of life and need for IVF in 1000 Italian infertile couples. Hum Reprod. 2005;20(5):1286-91. https://doi.org/10.1093/humrep/ deh788.

9. Verhaak CM, Aarts JWM, Boivin J, Kremer JAM, Van Empel IWH. O-038 measuring quality of life in infertility using the Fertiqol questionnaire. Hum Reprod. 2010;25(20100600):i16-7.

10. Valsangkar S, Bodhare T, Bele S, Sai S. An evaluation of the effect of infertility on marital, sexual satisfaction indices and health-related quality of life in women. J Hum Reprod Sci. 2011;4(2):80-5. https://doi.org/10.4103/ 0974-1208.86088.

11. Mousavi SA, Masoumi SZ, Keramat A, Pooralajal J, Shobeiri F. Assessment of questionnaires measuring quality of life in infertile couples: a systematic review. J Reprod Infert. 2013;14(3):110.

12. Cousineau TM, Domar AD. Psychological impact of infertility. Best Pract Res Clin Obstet Gynaecol. 2007;21(2):293-308. https://doi.org/10.1016/j.bpobgyn. 2006.12.003.

13. Luk BHK, Loke AY. The impact of infertility on the psychological well-being, marital relationships, sexual relationships, and quality of life of couples: a systematic review. J Sex Marital Ther. 2015;41(6):610-25. https://doi.org/10. 1080/0092623X.2014.958789

14. Peterson BD, Sejbaek CS, Pirritano M, Schmidt L. Are severe depressive symptoms associated with infertility- related distress in individuals and their partners? Hum Reprod. 2014;29(1):76-82. https://doi.org/10.1093/humrep/ $\operatorname{det} 412$.

15. Zurlo MC, Cattaneo Della Volta MF, Vallone F. Infertility-related stress and psychological health outcomes in infertile couples undergoing medical treatments: testing a multi-dimensional model. J Clin Psychol Med S. 2019. https://doi.org/10.1007/s10880-019-09653-z. 
16. Tennen H, Affleck G, Mendola R. Causal explanations for infertility: their relationship to control appraisals and psychological adjustment. In: Stanton AL, Dunkel-Schetter C, editors. Infertility. Perspectives from stress and coping research. New York, London: Plenum press; 1991. p. 109-131.

17. Wischmann T, Stammer H, Gerhard I, Verres R. Couple counseling and therapy for the unfulfilled desire for a child-the two-step approach of the "Heidelberg infertility consultation service". In: Strauss B, editor. Involuntary childlessness: psychological assessment, counseling, and therapy. Seattle, Toronto, Bern, Göttingen: Hogrefe \& Huber Publishers; 2002. p. 127-49.

18. Van den Broeck U, Emery M, Wischmann T, Thorn P. Counselling in infertility: individual, couple and group interventions. Patient Educ Couns. 2010;81(3):422-8. https://doi.org/10.1016/j.pec.2010.10.009.

19. The WHOQOL Group. The development of the World Health Organization Quality of Life Assessment Instrument (the WHOQOL). In: Orley J, Kuyken W, editors. Quality of Life Assessment: International Perspectives. Berlin Heidelberg: Springer; 1994.

20. Boivin J, Takefman J, Braverman A. Development and preliminary validation of the fertility quality of life (FertiQoL) tool. Hum Reprod. 2011a;26(8):208491. https://doi.org/10.1093/humrep/der171.

21. Boivin J, Takefman J, Braverman A. The fertility quality of life (FertiQoL) tool: development and general psychometric properties. Fertil Steril. 2011b;96(2): 409-15. https://doi.org/10.1016/j.fertnstert.2011.02.046.

22. Boivin J, Takefman J, Braverman A. FertiQoL International, Fertility Quality of Life Questionnaire [Questionario sulla qualità della vita prendendo in considerazione la fertilità]; 2008. Available from: http://sites.cardiff.ac.uk/ fertiqol/files/2015/02/fertiqol-Italian.pdf [Accessed 27th June 2018].

23. Chachamovich JR, Chachamovich E, Ezer H, Fleck MP, Knauth D, Passos EP. Investigating quality of life and health-related quality of life in infertility: a systematic review. J Psychosom Obstet Gynecol. 2010;31(2):101-10. https:// doi.org/10.3109/0167482X.2010.481337.

24. Aarts JWM, Van Empel IWH, Boivin J, Nelen WL, Kremer JAM, Verhaak CM. Relationship between quality of life and distress in infertility: a validation study of the Dutch FertiQoL. Hum Reprod. 2011;26(5):1112-8. https://doi. org/10.1093/humrep/der051.

25. Chachamovich JR, Chachamovich E, Zachia S, Knauth D, Passos EP. What variables predict generic and health-related quality of life in a sample of Brazilian women experiencing infertility? Hum Reprod. 2007;22(7):1946-52. https://doi.org/10.1093/humrep/dem080.

26. Abbey A, Andrews FM, Halman LJ. Psychosocial predictors of life quality: how are they affected by infertility, gender, and parenthood? J Fam Issues. 1994;15(2):253-71. https://doi.org/10.1177/0192513X94015002006.

27. Zurlo MC. Cattaneo Della Volta MF, Vallone F. predictors of quality of life and psychological health in infertile couples: the moderating role of duration of infertility. Qual Life Res. 2018;27(4):945-54. https://doi.org/10. 1007/s11136-017-1781-4

28. Karabulut A, Özkan S, Oğuz N. Predictors of fertility quality of life (FertiQoL) in infertile women: analysis of confounding factors. Eur J Obstet Gynecol Reprod Biol. 2013;170(1):193-7. https://doi.org/10.1016/j.ejogrb.2013.06.029.

29. Monga M, Alexandrescu B, Katz SE, Stein M, Ganiats T. Impact of infertility on quality of life, marital adjustment, and sexual function. Urology. 2004; 63(1):126-30. https://doi.org/10.1016/j.urology.2003.09.015.

30. Lau JT, Wang Q, Cheng Y, Kim JH, Yang X, Yi TH. Infertility-related perceptions and responses and their associations with quality of life among rural Chinese infertile couples. J Sex Marital Ther. 2008;34(3):248-67. https:// doi.org/10.1080/00926230701866117.

31. Onat G, Beji NK. Effects of infertility on gender differences in marital relationship and quality of life: a case control study of Turkish couples. Eur J Obstet Gynecol Reprod Biol. 2012;165(2):243-8. https://doi.org/10.1016/j. ejogrb.2012.07.033.

32. Chartier MJ, Walker JR, Naimark B. Separate and cumulative effects of adverse childhood experiences in predicting adult health and health care utilization. Child Abuse Negl. 2010;34(6):454-64. https://doi.org/10.1016/j. chiabu.2009.09.020.

33. De Venter M, Demyttenaere K, Bruffaerts R. The relationship between adverse childhood experiences and mental health in adulthood. A systematic literature review. Tijdschr Psychiatr. 2013;55(4):259-68.

34. Grandin LD, Alloy LB, Abramson LY. Childhood stressful life events and bipolar spectrum disorders. J Soc Clinl Psychol. 2007;26(4):460-78. https:// doi.org/10.1521/jscp.2007.26.4.460.

35. Heim C, Newport DJ, Wagner D, Wilcox MM, Miller AH, Nemeroff CB. The role of early adverse experience and adulthood stress in the prediction of neuroendocrine stress reactivity in women: a multiple regression analysis. Depress Anxiety. 2002;15(3):117-25. https://doi.org/10.1002/da.10015.

36. Wickrama KA, Lee TK, O'Neal CW. Stressful life experiences in adolescence and cardiometabolic risk factors in young adulthood. J Adolesc Health. 2015;56(4):456-63. https://doi.org/10.1016/j.jadohealth.2014.12.009.

37. Sokratous S, Merkouris A, Middleton N, Karanikola M. The association between stressful life events and depressive symptoms among Cypriot university students: a cross-sectional descriptive correlational study. BMC Public Health. 2013;13(1):1121. https://doi.org/10.1186/1471-2458-13-1121.

38. Corso PS, Edwards VJ, Fang X, Mercy JA. Health-related quality of life among adults who experienced maltreatment during childhood. Am J Public Health. 2008;98(6):1094-100. https://doi.org/10.2105/AJPH.2007.119826.

39. Edwards VJ, Anda RF, Felitti VJ, Dube SR. Adverse childhood experiences and health-related quality of life as an adult. In: Kendall-Tackett KA, editor. Application and practice in health psychology. Health consequences of abuse in the family: A clinical guide for evidence-based practice. Washington, DC, US: American Psychological Association; 2004. p. 81-94. doi:https://doi.org/10.1037/10674-005.

40. Salinas-Miranda AA, Salemi JL, King LM, Baldwin JA, Austin DA, Scarborough K, Spooner KK, Zoorobrj Salihu HM. Adverse childhood experiences and health-related quality of life in adulthood: revelations from a community needs assessment. Health Qual Life. 2015;13(1):123. https://doi.org/10.1186/ s12955-015-0323-4.

41. Sherbourne CD, Meredith LS, Rogers W, Ware JE. Social support and stressful life events: age differences in their effects on health-related quality of life among the chronically ill. Qual Life Res. 1992;1(4):235-46. https://doi. org/10.1007/BF00435632.

42. Pocnet C, Antonietti JP, Strippoli MPF, Glaus J, Preisig M, Rossier J. Individuals' quality of life linked to major life events, perceived social support, and personality traits. Qual Life Res. 2016;25(11):2897-908. https:// doi.org/10.1007/s11136-016-1296-4.

43. Wischmann, T. Heidelberger Kinderwunsch-Sprechstunde: eine Studie zu psychosozialen Aspekten ungewollter Kinderlosigkeit [Heidelberg fertility consultation service: a study of psychosocial aspect of involuntary childlessness]. Frankfurt/M: Peter Lang; 1998.

44. Wischmann T, Stammer H, Scherg H, Gerhard I, Verres R. Psychosocial characteristics of infertile couples: a study by the Heidelberg fertility consultation service. Hum Reprod. 2001;16(8):1753-61. https://doi.org/10. 1093/humrep/16.8.1753.

45. Wischmann T, Scherg H, Strowitski T, Verres R. Psychosocial characteristics of women and men attending infertility counselling. Hum Reprod. 2009;24(2): 378-85. https://doi.org/10.1093/humrep/den401.

46. Jacobs MB, Boynton-Jarrett RD, Harville EW. Adverse childhood event experiences, fertility difficulties and menstrual cycle characteristics. J Psychosom Obstet Gynecol. 2015;36(2):46-57. https://doi.org/10.3109/ $0167482 X .2015 .1026892$.

47. Gollenberg AL, Liu F, Brazil C, Drobnis EZ, Guzick D. Overstreet, Redmon JB, Sparks a, Wang C, swan SH. Semen quality in fertile men in relation to psychosocial stress. Fertil Steril. 2010;93(4):1104-11. https://doi.org/10.1016/j. fertnstert.2008.12.018.

48. Ebbesen SMS, Zachariae R, Mehlsen MY, Thomsen D, Højgaard A, Ottosen L, Petersen T, Ingerslev HJ. Stressful life events are associated with a poor invitro fertilization (IVF) outcome: a prospective study. Hum Reprod. 2008; 24(9):2173-82. https://doi.org/10.1093/humrep/dep185.

49. Nakamura K, Sheps S, Arck PC. Stress and reproductive failure: past notions, present insights and future directions. J Assist Reprod Genet. 2008;25(2-3): 47-62. https://doi.org/10.1007/s10815-008-9206-5.

50. Pottinger AM, Nelson K, McKenzie C. Stressful events and coping with infertility: factors determining pregnancy outcome among IVF couples in Jamaica. J Reprod Infant Psyc. 2016;34(1):3-14. https://doi.org/10.1080/ 02646838.2015.1093613.

51. Berghuis JP, Stanton AL. Adjustment to a dyadic stressor: a longitudinal study of coping and depressive symptoms in infertile couples over an insemination attempt. J Consult Clinl Psych. 2002;70(2):433-8. https://doi. org/10.1037/0022-006X.70.2.433.

52. Jordan C, Revenson TA. Gender differences in coping with infertility: a meta-analysis. J Behav Med. 1999;22(4):341-58. https://doi.org/10.1023/A: 1018774019232.

53. Kraaij V, Garnefski N, Schroevers MJ. Coping, goal adjustment, and positive and negative affect in definitive infertility. J Health Psychol. 2009;14(1):1826. https://doi.org/10.1177/1359105308097939. 
54. Peterson BD, Newton CR, Rosen KH, Skaggs GE. Gender differences in how men and women who are referred for IVF cope with infertility stress. Hum Reprod. 2006;21(9):2443-9. https://doi.org/10.1093/humrep/del145.

55. Peterson BD, Pirritano M, Christensen U, Schmidt L. The impact of partner coping in couples experiencing infertility. Hum Reprod. 2008;23(5):1128-37. https://doi.org/10.1093/humrep/den067.

56. Carver CS, Scheier MF, Weintraub JK. Assessing coping strategies: a theoretically based approach. J Pers Soc Psychol. 1989;56(2):267-83. https:// doi.org/10.1037/0022-3514.56.2.267.

57. Sica C, Magni C, Ghisi M, Altoè G, Sighinolfi C, Chiri LR, Franceschini S. Coping orientation problems experienced - Nuova versione italiana (COPENVI): Uno strumento per la misura degli stili di coping [coping orientation to the problems experienced-new Italian version (COPE-NVI)]. Psicoterapia Cognitiva e Comportamentale. 2008;14(1):27-53.

58. Gentili P, Contrearas L, Cassaniti M, D'Arista F. La dyadic adjustment scale. Una misura dell'adattamento di coppia [the dyadic adjustment scale. A measurement of dyadic adjustment]. Minerva Psichiatr. 2002;43(2):107-16.

59. Spanier GB. Measuring dyadic adjustment: new scales for assessing the quality of marriage and similar dyads. J Marriage Fam. 1976;38(1):15-28. https://doi.org/10.2307/350547.

60. Gameiro S, Boivin J, Dancet E, de Klerk C, Emery M, Lewis-Jones C, Thorn P, Van den Broeck $U$, Venetis $C$, Verhaak CM, Wischmann T, Vermeulen $N$. ESHRE guideline: routine psychosocial care in infertility and medically assisted reproduction - a guide for fertility staff. Hum Reprod. 2015;30(11): 2476-85. https://doi.org/10.1093/humrep/dev177.

\section{Publisher's Note}

Springer Nature remains neutral with regard to jurisdictional claims in published maps and institutional affiliations.

Ready to submit your research? Choose BMC and benefit from:

- fast, convenient online submission

- thorough peer review by experienced researchers in your field

- rapid publication on acceptance

- support for research data, including large and complex data types

- gold Open Access which fosters wider collaboration and increased citations

- maximum visibility for your research: over $100 \mathrm{M}$ website views per year

At BMC, research is always in progress.

Learn more biomedcentral.com/submissions 